\title{
The Premature Use of English Grammar by EFL Learners
}

\author{
Nur Mukminatien \\ Universitas Negeri Malang
}

\begin{abstract}
The roles of conscious learning and error corrections have been questioned since the development of communicative approaches to language teaching, along with theoretical and empirical insights from Second Language Acquisition (SLA) research. Whether overt learning really helps the learner produce better L2 performance is a mystery. This article describes the premature use of English Grammar by EFL learners as shown on their writing performance. It also reviews theoretical insights from SLA theories to uncover the mystery.
\end{abstract}

Key words: grammar, SLA, L2

A grammar class usually refers to a place where learners receive systematic instructions of linguistic rules, along with vocabulary and pronunciation of the language. The learners are provided with the opportunities to practice the new features of the language. Theknowledge derived from the conscious learning of the second language (L2) rules in the grammar class is expected to help the learners produce better L2 performance. Nevertheless, it seems that the learning of L2 grammar has little effect on helping the learners use the grammar rules productively. This paper tries to describe L2 learners' errors in writing. The errors would serve to provide evidence of the existing gap between what is learned and what is used, or, it shows the premature use of English grammar. It also reviews theoretical insights from SLA theories to answer why such a gap exists in the learners' L2 performance. The discussion begins with the position of grammatical competence in the broader construct of communicative competence (CC) in relation to the description of the gap. Then it discusses learners' structural errors as shown in their writing performance. It also provides explanations of the possible reasons 
for the existing gap between the learning of English Grammar and the ability in using it in written communication, focusing on the role of learning grammar in L2 performance. Finally, it discusses the limitations of language acquisition in EFL classes. Hopefully, this paper provides teachers of English with the fact about the gap between what is learned and what is used by the learners so that they do not expect too much of their students and force them to produce grammatically correct sentences merely because they assume that the students have learned a lot of grammar.

\section{GRAMMATICALCOMPETENCE}

A sentence-level grammatical competence has been placed into a proper perspective within the larger construct of communicative competence (CC) by Canale and Swain (1980) and Savignon (1983). The framework identifies the four components of CC as grammatical competence, sociolinguistic competence, discourse competence, and strategic competence. Grammatical competence refers to the learner's knowledge of language rules. It deals with the correctness of word formation or sentence structures. Sociolinguistic competence is the knowledge of the culture or the social rules of language. It requires the understanding of the social context in which the language is used appropriately. Discourse competence is the ability to connect utterances or sentences in stretches of utterances dealing with unity and coherence. The last component, the strategic competence, refers to the strategy to compensate for breakdowns in communication. It is the competence underlying one's ability to make repairs, to cope with imperfect knowledge, and to sustain communication through paraphrases, repetition, avoidance, guessing, and shifts in register and style. Based on the framework, grammatical accuracy is only part of communicative competence. On the other hand, the primary goal of communication is to convey a message, where grammar is merely a tool.

To communicate in written English, a writer needs sufficient knowledge of grammar as a tool to convey the intended message. In the Department of English Education, English Grammar is offered in three consecutive semesters (English Grammar I, English Grammar II, and English Grammar III) with four credit hours for English Grammar I and English Grammar II, and two credit hours for English Grammar III. Thus, within three semesters the students learn L2 rules explicitly with adequate exercise both in receptive and productive level. In consequence, they are expected and assumed to have gained comprehensive mastery of the English structure. As a matter of fact, however, the receptive level of $L 2$ rules does not seem to help the students apply the rules in the productive level. Their writing performance shows that they are grammatically incompetent due to the errors they makẹ.

The following section presents examples of errors which show how difficult it is to apply L2 rules in a communication task where the main goal is to convey a message.

\section{THE LEARNERS' STRUCTURAL ERRORS}

To describe the learners' errors, the following are samples of EFL learners' writing performance. They were adopted from three different groups of learners in the Department of English Education: (1) Pre Departure English Training Program,

(2) S1-Equivalent Program, or Program Penyetaraan S1 (a program which is specially offered to High School teachers who need to take their Sarjana Degree), and (3) Regular S1 students.

\section{Pre Departure English Training Program (PDETP)}

PDETP is a program designed for vocational teachers who are supposed to take a short course abroad for their professional development. They took a sevenweek intensive English course to prepare their departure. Here are their writing performance based on a given situation.

Situation: Your friend lost her book. You realized that you had borrowed it a month ago. Write a note of apology and explanation. 


\begin{tabular}{|l|l|}
\hline \multicolumn{1}{|c|}{ SAMPLE 1 } & \multicolumn{1}{c|}{ SAMPLE 2 } \\
\hline $\begin{array}{l}\text { Nia, } \\
\text { I'm afraid your book don't } \\
\text { lost. I borrow your book a } \\
\text { month ago. I don't } \\
\text { remember. I'm sorry its. I } \\
\begin{array}{l}\text { promise to return your book } \\
\text { in the afternoon }\end{array}\end{array}$ & $\begin{array}{l}\text { I'm sorry I forgot to return } \\
\text { becaure I came back my } \\
\text { village. If you don't mind, I } \\
\text { will return it. Thank you for } \\
\text { all see you. }\end{array}$ \\
\hline
\end{tabular}

Problems in expressing ideas into English lead to the production of errors, such as I'm afraid your book don't lost (sample 1) which should have been written ..... you didn't lose your book. Also, the use of its after I'm sorry .. does not represent an English sentence. Sample 2 contains problems of how to express I went back to my village and the learner wrote I came back my village. The errors indicate that the learners use Indonesian structure with English words. They cannot express guilty feelings and apology correctly and appropriately. The errors are not only in syntax (I'm afraid your book don't lost), but also in verb tenses (I borrow your book a month ago), and the missing of prepositions (I came back my village). The domination of L1 structure with L2 (English) word choice in production, according to Dulay et. al (1982) is called a premature use of $\mathrm{L} 2$ showing the learner's insufficient L2 competence.

\section{S1-Equivalent Program.}

The second sample was taken from an advanced English Grammar class (English Grammar III). The learners were a group of high school teachers from out of Java provinces. At the end of the semester they were assigned to write a paragraph to give opinion/comments on the current situation, the monetary crisis Sample 1

\section{Indonesia is Suffering from Monetary Crisis}

It seems that our country, Indonesia, have been facing a bad an crucial mon etary and economic problems for months. To face these problems we must help our government to overcome these problems by contributing whatever we have. It means that we do not only love our country, but also sacrifice for our country itself. For this reason, we are considered as good citizens.

Sample 2

\section{Stop Collecting Dollars}

As we know all Indonesia people is suffering from monetary and economic crisis. All prices are getting higher and higher. Meanwhile their income still low and stagnant. one of the problems is the value of Rupiah is weaker and weaker. To overcome this, we collect the Rupiah again and stop Dollars too much.

The two samples contain a lot of errors covering syntax errors, subject-verb agreement, article, the missing of to be, and inappropriate word choice. Syntax error appears in sample 2 as the first clause As we know all Indonesia people is suffering from monetary and economic crisis is not a sentence, so it should be attached to another clause. Subject-verb agreement error in sample 1, It seems that our country, Indonesia, have been facing a bad and crucial monetary and economic problems for months. The underlined word, should be has instead of have because the subject is singular. Sample 2 has the same error, ...people is suffering from .... Since the subject is people (plural), are should be used instead of $i s$. In terms of article used in sample $1, a$ is not necessary in ... a bad and crucial monetary and economic problems. because the noun is plural. The missing of to be appears in sample 2; Meanwhile, their income still low ... It needs is after its subject their income. A confusing idea arises in the use of overcome in sample $1 ; \ldots$ to overcome these problems... It seems that the intended meaning is to solve instead of to overcome.

The above samples of errors indicate that using English grammar is not as easy as understanding it. Even though they were English teachers who belonged to an advanced English Grammar class, their knowledge of L2 rules did not help them much improve their writing performance.

\section{Regular S1 Students}

In addition to the evidence of errors from classroom performance, the following evidence is part of research findings (Mukminatien 1997). It was a study 
designed to investigate the development of students' writing competence. One of the objectives of the study was to identify the learner's grammatical errors in their compositions focusing only on four dominant errors: subject-verb agreement, articles, pluralization, and syntax. The errors are indicated by underlines.

\section{a. Subject-Verb agreement}

Besides, TV today offer so many programs which is good according to us. This fast progressive make us very proud of our country.

The underlined words are errors in subject-verb agreement. They should have been written with $\{-s\}$ to indicate a third person singular.

\section{b. Articles}

Third problem is movements.

We can get the information about what happens in our countries.

The first sentence needs an article, while the second does not.

\section{c. Pluralization}

With its forests, farms, minings, water, and many others treasures, my country can be called "tanah surga" where woods and stones can become food.

The underlined word does not need a plural marker $\{-\mathrm{s}\}$

\section{d. Syntax}

In RCTI, Indonesia people can know what the news in their own country or in the world. Because of that knowledge can move progress than before.

Every field is need English, and English has to be studied by people, so people will not be fool.

The sentences are incorrect syntactically. The ideas expressed are confusing as they are not put in a correct sentence construction
In fact, it is obvious that almost every sentence produced by the students contains more than one category of errors. For example, In addition to the problems of subject-verb agreement, students also found problems in word formation as in This fast progressive make us very proud of our country. It should be This progress makes us very proud of our country. It leads to the conclusion that applying rules which are assumed to have been learned in the grammar class is a big problem when it comes to the communicative task, or, writing. Then a big question arises whether conscious learning and error correction do help produce better performance. The rest of this discussion will try to answer the question based on the theoretical insights from SLA theories to find out the role of grammar in L2 performance and the limitation of language acquisition in EFL classes.

\section{THE ROLE OF GRAMMAR IN L2 PERFORMANCE}

Concerning English Grammar classes in the English Department, it has been commonly known that the classes provide explicit learning of linguistic rules. The activities cover rule explanation along with exercises focussing on the understanding and the use of the grammatical items. At the end of the course the students are expected to be able to apply the rules to help improve their performance both in speaking and writing. However, the fact shows that the learners are unable to apply them in a communicative task.

In the development of theoretical and empirical insights from SLA research, the role of grammar in foreign/second language teaching has been uncertain. The efficacy of a grammatically structured syllabus and the role of error corrections have been questioned. To answer the question, it is necessary to take a closer look at what errors mean in SLA theory.

Errors, viewed from SLA theories, are evidence of the systematic development of $\mathrm{L} 2$ rules showing the system of rules that a learner has developed at a particular stage called transitional competence (Corder, 1967). People acquiring a second language naturally are thought to progress along a continuum whose poles are their first language and the target language. In developing L2 competence, learners pass through a series of stages. This sequence of stages is called interlanguage by Selinker (1972). Each stage is more complex than the one pre- 
ceding it, complexity being defined in terms of the limit on short term memory (Nunan, 1992:147). The concept of interlanguage continuum is useful in the classroom as well as in studying naturalistic language acquisition. It is the teacher's job, according to Allwright and Bailey (1991), to help learners move along the interlanguage continuum smoothly and correctly.

Concerning the ability to produce complex sentences, Dulay et al. (1982) state that long and complex sentences are difficult to learn. In other words, the ability to produce complex utterances/ sentences comes from acquisition processes but not from conscious learning. This supports Krashen's Monitor theory stating that conscious learning has an extremely limited function in adult second language performance. The learned rules would be useful only for repairing the production of the acquired rules.

The SLA theory leads to the idea that the goal of learning grammar in a language program is to produce optimal monitor users. The performers can use the knowledge of grammar as a supplement to acquisition in a situation where grammar use is appropriate (Krashen and Terrel, 1984). They also state that teachers should not expect their students to be concerned with fine points of grammar while they are speaking in free conversation; rather, the time to use the monitor is in writing and in prepared speech. Indeed, it implies that the learned rules from grammar instructions will only be used in monitoring production where possible.

The samples of students' errors in writing sentences prove that learning experience in Grammar classes has a little effect on students' writing performance. The facts support the belief that mastery in grammar does not guarantee a proficient use of the language (Dulay et al. 1982: 20). The theoretical explanation can be obtained from SLA theories especially the distinction between acquisition and learning. The terms are popularized by Krashen (1981) to describe how adult learners learn a new language. He makes a distinction between subconscious process of internalizing linguistic rules (in natural communication) called acquisition and the conscious process (overt learning such as that in a grammar class) called learning. He believes that the acquired rules are responsible for initiating spontaneous production while the learned rules serve only as a monitor to edit the utterances for accuracy (Krashen's Monitor Model). This model clarifies the different roles of acquisition and learning in production The model has been elaborated by Stevick's and Bialystok's Model (Huda, 1984). The Stevick's Model does not strictly separate learning and acquisition because according to the theory, after a long period in an intensive practice, the learned rules can become acquired, and thus, they could serve to initiate production (output).

\section{THE LIMITATION OF LANGUAGE ACQUISITION IN EFL} CLASSES

To uncover the mystery of the gap between what is learned and what is used, the discussion goes to the limitation of language acquisition in EFL classes. Concerning the SLA theory, it is believed that the learner's ability to produce the target language is a result of acquisition. Therefore, to produce L2, the learner needs sufficient acquired rules to begin with. In English classes in Indonesia, the proportion of learning process is commonly bigger than the acquisition process (Nababan, 1991). It means that the students are provided more with situations for learning than for acquisition. Consequently, when they are forced to write, they do not have sufficient rules to begin with. Furthermore, if the English teachers do not use English naturally in the classroom, the students will lose the opportunity to be exposed to the target language in a natural environment. In other words, the students have a very limited opportunity to have natural linguistic input necessary for acquisition. To make matters worse, as naturally not all the available input is processed by the learners (Ellis, 1986:127), accordingly they have insufficient acquired linguistic rules needed for production.

In such a condition, if a learner is forced to write when he/she is not ready (because of the limited competence), he/she will usually show a premature use of the L2 reflecting L1 structure (Dulay et al., 1982:111). This is because in an EFL situation, the pressure to produce the new language comes from the requirements of classroom performance. The problem is even worse when it is connected to the critical point of acquisition in relation to age differences in SLA. The general characteristic of foreign language learning tends to lead to the conclusion that the domain-specific language acquisition system of children ceases to operate in adults (Gass and Schachter, 1990:49-55). This has been believed as substantial obvious 
differences between child language development and adult language learning. In adults, the language acquisition device (LAD) ceases to operate, but the knowledge of L1 and other general problem solving serve as imperfect substitutes (Dulay et al., 1982; Gass and Schachter, 1990).

Those explanations provide a clear answer to such a question as why overt learning of linguistic rules in a grammar class does not help much in improving the accuracy of the students' performance. The samples show that the learners in the study did not have sufficient acquired rules to write with; therefore, they produced their sentences which were dominated by interlingual errors including language transfer.

Considering that English teaching in Indonesia begins at junior high schools, teachers expect their students to have a good command of English after graduating from the senior high-schools. Unfortunately, after a six-year learning experience, they are still in the premature level. Even the students of the English Department who have taken a three-semester Grammar classes find difficulties applying the L2 rule systems. If the goal of a grammar class in the English Department is to produce optimal monitor users, it seems that all the requirements to use a monitor is fulfilled (they have enough time, focus on the form in editing, and know the rules). Apparently, they had enough time to write and to focus on forms, and they also might have thought about correctness when they reviewed and edited their sentences. In this case, however, it is quite possible that even when they had time, they might not be concerned with whether they had written the sentences correctly, rather, with what to write and how to write it. The third requirement is that the learner should have the knowledge of the rules. This is really a big question. "Did the students know the rules?" Based on the assumption that they did know the rules in the grammar class, the answer should be "Yes" because they had learned grammar for three consecutive semesters. Did they forget the rules when they wrote the essay? The answer may be "Yes". Or, they did not forget the rules, but they had not yet internalized the rules while learning in the Grammar class.

\section{CONCLUSION}

The discussion has led to the conclusion that grammar has a very limited role in the learner's performance. What is learned is not always available for use in a real communication. Those who have learned $\mathrm{L} 2$ rules are not always good in applying the rules in performing a communicative task. The gap between learning and using L2 rules is due to the different roles of acquisition and learning in the learners' L2 development. Therefore, English teachers are suggested not to expect too much to their students merely because they assume that the students have learned much of English Grammar. The main problem lies on the insufficient acquired rules due to lack of natural exposure to the language.

\section{REFERENCES}

Allwright, Dick and Bailey, Kathleen M. 1991. Focus on the Language Classroom. Cambridge: Cambridge University Press.

Canale, Michael and Swain, Meril. 1980. Approaches to Communicative Competence. Singapore: SEAMEO Regional Language Center.

Corder, S.P. 1967. The Significance of Learners' Errors. In Richards, Jack. C. 1980 (Ed.). Error Analysis. Perspective on Second Language Acquisition. (pp. 19-30)

Dulay, Heidi; Burt, Marina; and Krashen, Stephen D. 1982. Language Two. Oxford: Oxford University Press

Ellis, Rod. 1986. Understanding Second Language Acquisition. Oxford: Oxford University Press.

Gass, Susan M. and Schachter, Jacquelyn. 1990. Linguistic Perspective on Second Language Acquisition. Cambridge: Cambridge University Press.

Huda, Nuril. 1984. Orders of Acquisition of Monitored and Unmonitored Enolish Morphemes by Indonesian-Speaking Students. Unpublished dissertation. Austin: The University of Texas at Austin.

Krashen, Stephen D. 1981. Second Language Acquisition and Second Language Learning. Cambridge: Cambridge University Press.

Krashen, Stephen D. and Terrel, Tracy D. 1983. The Natural Approach. Language Acquisition in the Classroom. Oxford: Oxford University Press.

Mukminatien, Nur. 1997. The Differences of Students' Writing Achievements Across Different Course Levels. Unpublished Dissertation. Malang: IKIP MALANG.

Nababan, P.W.J. 1991. Language Acquisition in an EFL Classroom. Possibilities and Limitations, TEFLIN Journal, 4(2): 45-62.

Nunan, David. 1991. Language Teaching Methodology. A Textbook for Teachers. New York: Prentice-Hall 
Savignon, Sandra J. 1983. Communicative Competence: Theory and Classroom Practice. Texts and Contexts in Second Language Learning. Reading: Addison-Westley Publishing Company.

Selinker, Larry. 1972. Interlanguage. In Richards, Jack C. (Ed.) 1980. Error Analysis. Perspective on Second Language Acquisition (pp. 31- 54). 